\title{
Cross-reactions in cell mediated Immunity induced by atypical mycobacteria
}

\author{
SWATI KULKARNI and R. S. KAMAT
}

Department of Immunology, Haffkine Institute, Bombay 400012, India.

\begin{abstract}
Summary. Cross-reactivity in the delayed hypersensitivity response to mycobacteria of different Runyon groups was tested in Swiss white mice immunised with live mycobacteria. All the strains tested gave cross-reactions and, generally, slow growers gave stronger cross-reactions with other slow growers than with rapid growers and vice versa. Sonicates of cross-reacting mycobacteria were also tested for their ability to generate activated macrophages in mice immunised with Mycobacterium avium. All the mycobacterial sonicates generated activated macrophages but a sonicate of Salmonella typhi did not. The sonicate of $M$. tuberculosis $\mathrm{H} 37 \mathrm{Rv}$ also generated activated macrophages, which indicates that there might be protective cross-reactions between $M$. tuberculosis and atypical mycobacteria.
\end{abstract}

\section{Introduction}

Atypical mycobacteria are common in the tropical environment. The majority of them are of either low or no virulence for man but many cause inapparent infections. Theoretically, such infections could be expected to alter the immune status of the host not only against the causative organism but also against the classically pathogenic mycobacteria, if the two were antigenically related. Classifications based on diverse metabolic characters need not necessarily reflect immunological relationships, particularly with reference to cell-mediated immunity which is considered to be important in mycobacterial infections. Palmer and Long (1966) and Shield et al. (1979) have proposed that a modification of the host's immune status by atypical mycobacterial infection is a possible explanation for the reported failure of BCG vaccination in certain studies. Magnusson (1961) and Chaparas and Maloney (1978) have reported extensive crossreactivity between sensitins prepared from different mycobacteria. However, because the delayed hypersensitivity skin test is not considered to be necessarily an index of protective cell-mediated immunity, the reported cross-reactions between mycobacteria have often been ignored. In this paper, we present evidence to show that the delayed hypersensitivity cross-reactions of atypical mycobacteria both amongst themselves and with classical pathogenic mycobacteria correlate closely with an in-vitro index of protective cell-mediated immunity.

Received 31 Aug. 1984; accepted 15 Jan. 1985.

Requests for reprints should be sent to Dr. R. S. Kamat.

\section{Materials and Methods}

\section{Bacteria}

Mycobacterium tuberculosis H37Rv (NCTC7416), $M$. kansasi NCTC10268, $M$. marinum NCTC2275, M. flavescens NCTC10271, $M$. avium NCTC8559, $M$. intracellulare NCTC10425, M. phlei NCTC8151 and Salmonella typhi $(0: 9,12, \mathrm{Vi}, \mathrm{H}: \mathrm{d}) \mathrm{NCTC} 8385$ were obtained from the National Collection Of Type Cultures, Colindale Avenue, London NW9 5HT. M. vaccae and M. scrofulaceum were kindly supplied by Dr J. L. Stanford, Middlesex Hospital, London. S. enteritidis $(\mathrm{O}: 1,9,12 \mathrm{H}: \mathrm{g}, \mathrm{m})$ was isolated from naturally infected mice in the animal colony of the Haffkine Institute.

\section{Animals}

Swiss white mice were obtained from the National Institute of Health, USA and maintained in the animal colony of Haffkine Bio-Pharmaceutical Corporation Limited.

\section{Immunisation}

Four to six-week-old mice weighing 18-20 g were immunised intraperitoneally with $2-4 \mathrm{mg}$ of cells of $M$. avium (nonchromogen), $M$. scrofulaceum (scotochromogen) or M. kansasi (photochromogen), suspended in 0.5

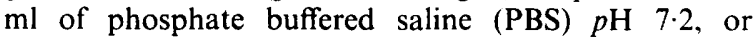
intradermally with $10^{7}$ live cells of $M$. vaccae in $0.01 \mathrm{ml}$ of PBS.

\section{Sonic extracts of bacteria}

Strains of mycobacteria were grown on the medium of Doub and Youmans (1950) for 4-6 weeks for the slow growers and for one week for the rapid growers. They were killed by exposure to 2.4 megarad of $\gamma$-irradiation from a ${ }^{60} \mathrm{Co}$ source. The killed cells were washed with PBS, disrupted by sonication (Branson B-30 Sonicator) 
and centrifuged at $50000 \mathrm{~g}$ for $1 \mathrm{~h}$. The supernates were used as the test antigens after standardising the protein content by the method of Lowry et al. (1951). The sonic extract of $S$. typhi was prepared in a similar manner from an overnight culture on nutrient agar. The sonicate was then centrifuged at $100000 \mathrm{~g}$ for $1 \mathrm{~h}$ to remove lipopolysaccharides and the supernate was used as antigen after standardisation of the protein content.

\section{Footpad swelling test for delayed hypersensitivity}

This test was performed by the method of Gray and Jennings (1955). An 0.03-ml volume of the sonicate of the immunising strain containing $50 \mu \mathrm{g}$ of protein was injected into one hind footpad and the same volume of the sonicate of one of the other mycobacterial species in the other to detect cross-reactivity. The footpad thicknesses were measured before, and 24 and $48 \mathrm{~h}$ after injection. Non-immune mice served as controls and all sonicates were tested in these. Each sonicate was tested in at least five mice that gave a positive delayed hypersensitivity response to the sonicate of the immunising species. The results were expressed as "corrected footpad enlargement" which is the difference between the footpad enlargement caused by a test sonicate in the immunised and in the control mice.

\section{Generation of activated macrophages}

Mice immunised with $M$. avium 3 months earlier were given intraperitoneal injections of the sonicate of either $M$. avium or S. typhi; both sonicates contained $100 \mu \mathrm{g}$ of protein in $0.5 \mathrm{ml}$ PBS. The microbicidal activity of the cells in the peritoneal exudate was assayed $36 \mathrm{~h}$ later (see below). Similarly immunised mice were given intraperitoneal injections of $100 \mathrm{ug}$ of a sonicate of one of the three mycobacteria that had produced cross-reactions in the delayed hypersensitivity test $-M$. tuberculosis $\mathrm{H} 37 \mathrm{Rv}$, $M$. kanasisi and $M$. vaccae. The microbicidal activity of the cells in the peritoneal exudate was assayed $36 \mathrm{~h}$ later (see below).

\section{Microbicidial activity of peritoneal exudate cells}

The assay described by Nair and Kamat (1982) was used. Each mouse was given an intraperitoneal injection of $c .2 \times 10^{4} \mathrm{cfu}$ of smooth $S$. enteritidis preopsonised with heat-inactivated rabbit antibody to $S$. enteritidis. They were killed by cervical dislocation exactly $5 \mathrm{~min}$ later. Chilled Hanks's Balanced Salts Solution (HBSS) $2 \mathrm{ml}$, containing heat-inactivated rabbit antiserum against heat-killed $S$. enteritidis $2 \% \mathrm{v} / \mathrm{v}$, new-born calf serum $10 \%$ $\mathrm{v} / \mathrm{v}$ and heparin $20 \mathrm{IU}$, was immediately injected intraperitoneally into each mouse; the abdomen was massaged and the contents aspirated. The peritoneal exudate cells from several mice were pooled and washed and the number of cfu of unphagocytosed bacteria in the washings assayed. The pellet of washed peritoneal exudate cells was suspended $\left(c .6 \times 10^{6}\right.$ cells $\left./ \mathrm{ml}\right)$ in warm HBSS containing newborn calf serum $12 \% \mathrm{v} / \mathrm{v} ; 1-\mathrm{ml}$ portions were incubated at $37^{\circ} \mathrm{C}$ for various periods and one portion was chilled immediately. After incubation, $0.1 \mathrm{ml}$ of saponin was added to give a final concentration of $2.5 \%$ $\mathrm{v} / \mathrm{v}$ to lyse the peritoneal exudate cells. Lysates were kept on ice until dilution and plating for viable bacterial counts. The percentage of the number of cfu injected killed at each time was calculated.

\section{Results}

\section{Cross-reactions in delayed hypersensitivity tests}

The table shows the extent of the cross-reactions that occurred when mice immunised with $M$. kansasi, $M$. scrofulaceum, $M$. avium or $M$. vaccae were challenged with various mycobacterial antigens. There were extensive cross-reactions with all the mycobacteria, but in general slow growing strains gave stronger cross reactions with other slow growing strains than with rapid growers, and rapid growers gave stronger cross reactions with other rapid growers. $M$. tuberculosis $\mathrm{H} 37 \mathrm{Rv}$ cross-reacted with both slow and rapid growers.

\section{Generation of activated macrophages by sonicates of mycobacteria}

Peritoneal exudate cells of mice immunised 3 months earlier with $M$. avium, but not stimulated with a sonicate before the assay, phagocytosed and killed $15 \%$ of challenge salmonellae in $5 \mathrm{~min}$ and $21 \%$ in $25 \mathrm{~min}$. After stimulation with the $M$. avium sonicate, the microbicidal activity of the peritoneal exudate cells was enhanced and $60 \%$ of challenge salmonellae were phagocytosed and killed in $5 \mathrm{~min}$ and $72 \%$ in 35 mins. When the mice were stimulated with the $S$. typhi sonicate instead of the $M$. avium sonicate, there was no enhancement of the microbicidal activity of the peritoneal exudate cells. The peritoneal exudate cells of non-immune normal mice stimulated with the $M$. avium sonicate killed $35 \%$ of challenge salmonellae in 5 min (fig la). The differences between the percentages of salmonellae killed by mycobacterium-stimulated macrophages from immunised mice and the percentages killed by non-immune or unstimulated or S. typhi-stimulated macrophages at each time were highly significant ( $\mathrm{p}<0.01$; Student's $t$ test).

The microbicidal activity of the peritoneal exudate cells of mice immunised with $M$. avium was also enhanced by stimulation with the sonicates of $M$. tuberculosis, M. kansasi or M. vaccae. For example, the peritoneal exudate cells of mice stimulated with the sonicate of $M$. tuberculosis killed $53 \%$ of challenge salmonellae in $5 \mathrm{~min}$. By comparison, cells from non-immune normal mice stimulated with the sonicate killed only $25 \%$ of challenge salmonellae in 5 min (fig. 1b). The differences in the percentages of salmonellae killed in the various assays were highly significant $(\mathrm{p}<0.01$, Student's $t$ test). The microbicidal profiles of the peritoneal exudate cells from mice stimulated with the other 
Table Delayed hypersensitivity cross-reactivity of mycobacteria

\begin{tabular}{|c|c|c|c|c|}
\hline \multirow[b]{2}{*}{ Test antigen } & \multicolumn{4}{|c|}{ Corrected foot pad enlargement at $48 \mathrm{~h}$ in mice immunised with } \\
\hline & M. kansasi & M. scrofulaceum & M. avium & M. vaccae \\
\hline M. tuberculosis $\mathrm{H} 37 \mathrm{Rv}$ & $0 \cdot 1312 \pm 0.02^{*}$ & $0 \cdot 0700 \pm 0 \cdot 03$ & $0.0937 \pm 0.03$ & $0.0714 \pm 0.01$ \\
\hline M. kansasi & $0 \cdot 2051 \pm 0 \cdot 01$ & $0 \cdot 1042 \pm 0.03$ & $0 \cdot 1375 \pm 0 \cdot 03$ & $0 \cdot 1300 \pm 0 \cdot 04$ \\
\hline M. marinum & $0.0862 \pm 0.02$ & $\mathrm{NT}$ & NT & NT \\
\hline M. scrofulaceum & $0 \cdot 1104 \pm 0.02$ & $0 \cdot 1984 \pm 0 \cdot 01$ & $0.1083 \pm 0.02$ & $0.1117 \pm 0.05$ \\
\hline M. flavescens & NT & $0.1112 \pm 0.03$ & NT & NT \\
\hline M. avium & $0.0762 \pm 0.03$ & $0.1275 \pm 0.02$ & $0.2319 \pm 0.02$ & $0.0881 \pm 0.04$ \\
\hline M. intracellulare & NT & NT & $0 \cdot 1770 \pm 0.02$ & NT \\
\hline M. vaccae & $0.0675 \pm 0.03$ & $0.0750 \pm 0.03$ & $\uparrow 0.0187 \pm 0.02$ & $0.1958 \pm 0.04$ \\
\hline M. phlei & $0.0763 \pm 0.02$ & $0.0767 \pm 0.02$ & $0.0542 \pm 0.01$ & $0.1100 \pm 0.01$ \\
\hline
\end{tabular}

$\mathrm{NT}=$ Not tested

$* 95 \%$ confidence limits. All the corrected foot pad enlargement responses are statistically significant $(p<0.05)$ except the one marked†.

a

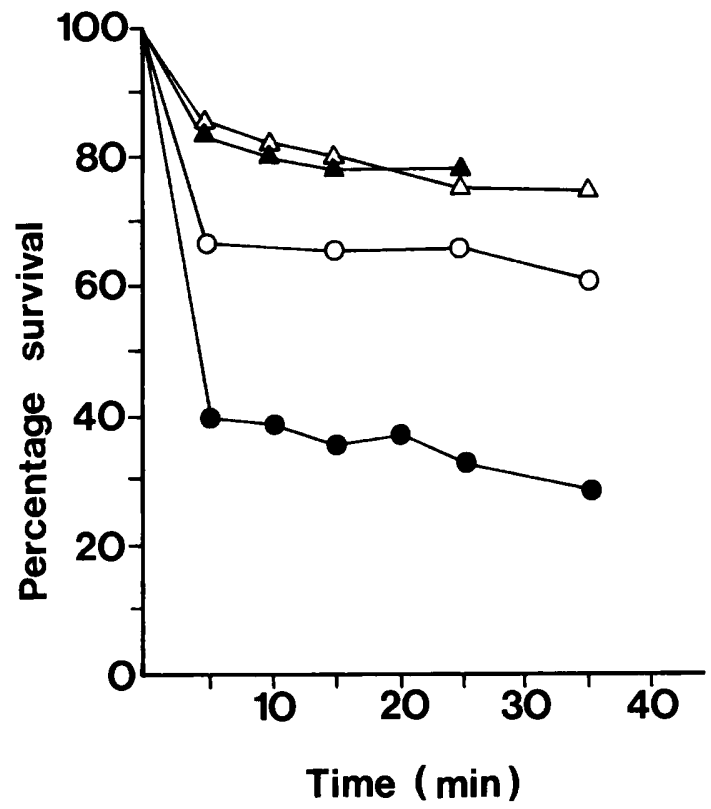

b

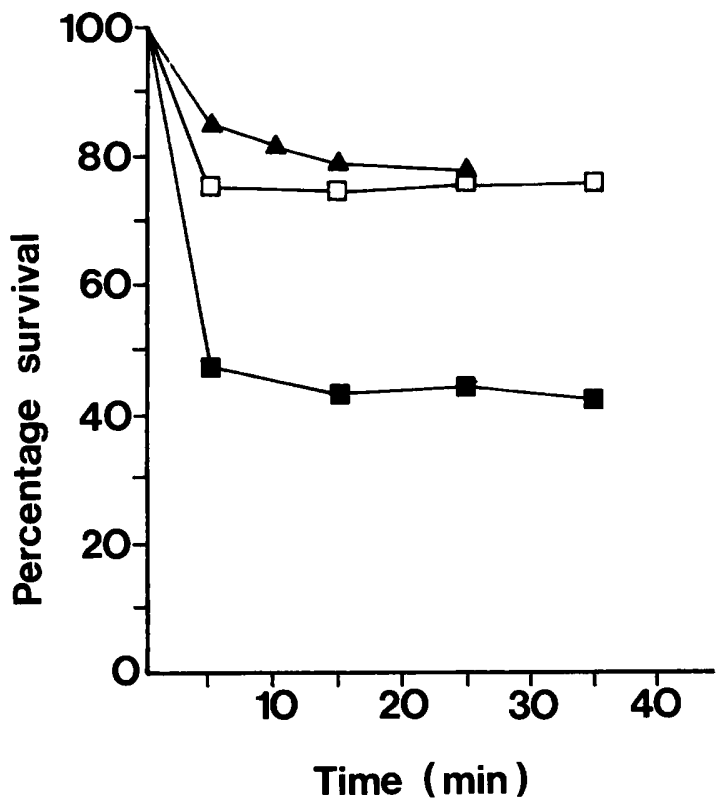

Fig. Microbicidal activity of pooled peritoneal exudate cells of mice: not immunised but stimulated with the sonicate of $M$ avium (O) or $M$. tuberculosis H37Rv ( $\square$ ); immunised with live $M$. avium and not stimulated (A) or stimulated with the sonicate of either $M$. avium $(\bullet)$ or M. tuberculosis H37Rv (ם) or S. typhi $(\Delta)$.

mycobacterial sonicates showed similar enhancement.

\section{Discussion}

Extensive cross-reactions between mycobacteria belonging to different groups have been reported in delayed hypersensitivity tests with mycobacterial extracts or 'sensitins' (Magnusson, 1961; Chaparas and Maloney, 1978). Such cross-reactions have been considered to be non-specific (Daniel and Janicki, 1978) and not a true recognition by effector $\mathrm{T}$ cells generated by cross-reacting mycobacterial immunisation. Recently, Hattikudur and Kamat
(1984) have characterised an antigen of $M$. tuberculosis $\mathrm{H} 37 \mathrm{Rv}$ that elicited a delayed hypersensitivity response and also generated activated macrophages by interaction with effector $T$ cells. In a separate report the same authors (Hattikudur and Kamat, $1985)$ showed that this antigen is highly polymorphous and has group-specific and genus-specific determinants on the same molecule. In view of this, cross-reactivity amongst mycobacteria as measured by delayed hypersensitivity may be due to recognition by $\mathrm{T}$ cells of cross-reactive determinants on a shared antigen or antigens. Hence it was logical to investigate if these antigens would also generate activated macrophages by interaction with effector 
$\mathrm{T}$ cells generated in animals immunised with crossreacting mycobacteria. Because activated macrophages are essential for controlling infections with facultative intracellular bacteria (Collins, 1974), their generation by cross-reactive $\mathrm{T}$-cell-antigen interaction can be considered as an index of true protective cross-immunity.

As expected, sonicates of all the mycobacteria that gave cross-reactions with $M$. avium generated activated macrophages in mice immunised with $M$. avium. It could be argued that the observed enhancement of microbicidal activity of peritoneal exudate cells is due to the well known non-specific adjuvant effect of mycobacterial antigens. This was refuted by showing that the enhancement of microbicidal activity of peritoneal exudate cells from nonimmune mice by stimulation with the various mycobacterial sonicates was not comparable with that obtained when cells from mice immunised with $M$. avium were stimulated (figs $1 \mathrm{la}$ and $\mathrm{b}$ ).

Immunological specificity of these cross-reactions was proved by showing that after stimulation of mice immunised with $M$. avium with $S$. typhi sonicate there was no enhancement of microbicidal activity of peritoneal exudate cells.

Because of the practical difficulty of enumerating surviving mycobacteria as $\mathrm{cfu}$, it was not possible to use them in an assay of bacterial killing by the macrophages. Activated macrophages are nonspecific in their killing potential (Mackaness, 1964), and salmonellae, being facultative intracellular parasites (Suter, 1956), can be killed efficiently by

\section{REFERENCES}

Chaparas S D, Maloney C J 1978 An analysis of cross-reactions among mycobacteria by in vivo and in vitro assays of cellular hypersensitivity, American Review of Respiratory Diseases 117:897-902.

Collins F M 1971. Immunogenicity of various mycobacteria and the corresponding levels of cross-protection developed between species. Infection and Immunity 4:688-696.

Collins F M 1974. Vaccines and cell-mediated immunity. Bacteriological Reviews 38:371-402.

Daniel T M, Janicki B W 1978 Mycobacterial antigens: a review of their isolation, chemistry and immunological properties. Microbiological Reviews 42:84-113.

Doub L, Youmans G P 1950. Studies in tuberculosis chemotherapy. 1 . Simple primary aromatic amines, in vitro and in vivo. American Review of Tuberculosis 61:407-421.

Gray D F, Jennings P A 1955 Allergy in experimental mouse tuberculosis. American Review of Tuberculosis 72:171-195.

Hattikudur S, Kamat R S 1984. Characterisation of target antigen of cell-mediated immunity in Mycobacterium tuberculosis H37Rv. Journal of Medical Microbiology 18:17-25.

Hattikudur S N, Kamat R S 1985 Polymorphism of a mycobacterial antigen participating in CMI, Journal of Medical Microbiology 19:69-75.

Lefford M J, Logie P S 1981 Induction and suppression of crossreactive antituberculosis immunity after Mycobacterium activated macrophages only. Therefore, challenge with $S$. enteritidis was used to assay the generation of activated macrophages. The specificity of cellmediated immunity was demonstrated in our experiment by the interaction of effector $T$ cells with antigens of the sonicates that was essential for generation of activated macrophages. However, caution is necessary in interpreting these data because activation to kill salmonellae may not necessarily imply enhanced mycobactericidal activity.

Several investigators have reported in-vivo studies of cross-protective immunisation with mycobacteria. Collins (1971) reported variable efficacy in mice of intravenous vaccines of live cells of several mycobacterial species in affording protection against challenge with $M$. tuberculosis. Shepard et al. (1980) have shown induction of cross-protection against $M$. leprae by BCG. However, in such studies, where the challenge was given to the vaccinated animal, it is difficult to rule out the nonspecific protection induced by activated macrophages generated by vaccination itself. On the other hand, Lefford and Logie (1981) showed crossprotection against $M$. lepraemurium in mice by adoptive transfer of immune $T$ cells generated by BCG vaccination and vice versa. Our findings lend further support to the hypothesis that natural infections with atypical mycobacteria modify the immune status towards classically virulent mycobacteria or BCG vaccination or both, as proposed by Palmer and Long (1966) and Shield et al. (1979).

lepraemurium infection of mice. Infection and Immunity 31 : 1023-1033.

Lowry O H, Rosebrough N J, Farr A L, Randall R J 1951 Protein measurement with the Folin phenol reagent. Journal of Biological Chemistry 193:265-275.

Mackaness G B 1964. The immunological basis of acquired cellular resistance, Journal of Experimental Medicine 120: 105-120.

Magnusson M 1961 Specificity of mycobacterial sensitins. (I) Studies in guinea pigs with purified "tuberculin" prepared from mammalian and avian tubercle bacilli, Mycobacterium balnei and other acid-fast bacilli American Review of Respiratory Diseases 83:57-68.

Nair R, Kamat R S 1982. Effector cell-mediated immune response in mice immunised with Salmonella. Journal of Medical Microbiology 15:215-221.

Palmer C E, Long M W 1966 Effects of infection with atypical mycobacteria on BCG vaccination and tuberculosis American Review of Respiratory Diseases 94:553-568.

Shepard C C, Van Landingham R, Walker L L 1980 Searches among mycobacterial cultures for anti-leprosy vaccines. Infection and Immunity 29: 1034-1039.

Shield M J, Stanford J L, Rook G A W 1979 The reason for the reduction of the protective efficacy of BCG in Burma. International Journal of Leprosy 47:319-320.

Suter E 1956 Interaction between phagocytes and pathogenic microorganisms. Bacteriological Reviews 20:94-132. 